\title{
The Color Expressions in the Traditional Costumes of Taiwanese Indigenous Peoples
}

\section{Las expresiones de color en los trajes tradicionales de los pueblos indígenas taiwaneses}

DOI: $10.46932 /$ sfjdv2n5-089

Received in: Oct 1st, 2021

Accepted in: Dec 30th, 2021

\author{
Wang Pohsun \\ Doctor of Philosophy in Design \\ Faculty of Innovation and Design, City University of Macau \\ K.C. Wong Building, Avenida Padre Tomás Pereira Taipa, 999078 Macau \\ E-mail: g9730801@gmail.com \\ Zhou Junling \\ Doctor of Urban Planning and Design \\ College of Fine Arts, Guangdong Polytechnic Normal University \\ 293 Zhonghshan Dadao, Tianhe District Guangzhou, Guangdong, 510633 China \\ E-mail: 531748238@qq.com
}

\begin{abstract}
With respect to both fiber and color the clothing material of Taiwan's indigenous people came predominantly from nature. Atayal woven materials are a distinct example of how ethnic symbolism can be expressed through the combining of color and fabric patterns in weaving and dying. In order to understand Atayal fabric color use and distribution, this research first utilizes PANTONE FASHION + HOME cotton planner to contrast fabric color, and after comparison, color specimens are input one at a time into Color Schemer Studio's color wheel statistics system. In order to analyze Atayal fabric colors, this study particularly performs color scope analysis on sub-groups for which research specimens are relatively abundant, such as the Tayal's Beishi group and Nanao Group; and the Sediq's Wushe Group, Wanda Group, and Taroko Group. Beishi group fabrics use a comparatively wide range of color and a more diverse number of combinations. The main colors they use include white, red, orange, yellow, green, blue, and other colors. The colors used by the Wushe Group and Wanda Group in their fabrics include white, red, blue and others. While the number of specimens collected for this study is limited, it is possible to understand, what the color preferences of sub-tribes are through their color schemes. The most predominant color schemes involve similar colors, contrasting colors, and complimentary colors.
\end{abstract}

Keywords: Indigenous peoples, Atayal, fabrics, color.

\section{RESUMEN}

Tanto en lo que respecta a la fibra como al color, el material de las prendas de vestir de los pueblos indígenas de Taiwán procedía predominantemente de la naturaleza. Los tejidos Atayal son un claro ejemplo de cómo el simbolismo étnico puede expresarse a través de la combinación de patrones de color y de tejido en la confección y el teñido. Para entender el uso y la distribución del color de los tejidos Atayal, esta investigación utiliza primero el planificador de algodón PANTONE FASHION + HOME para contrastar el color del tejido y, tras la comparación, se introducen muestras de color de una en una en el sistema estadístico de la rueda de color de Color Schemer Studio. Para analizar los colores de los 
tejidos del Atayal, este estudio realiza en particular el análisis del alcance del color en los subgrupos para los que los especímenes de investigación son relativamente abundantes, como el grupo Beishi y el grupo Nanao del Tayal; y el grupo Wushe, el grupo Wanda y el grupo Taroko del Sediq. Los tejidos del grupo Beishi utilizan una gama de colores comparativamente más amplia y un número más diverso de combinaciones. Los principales colores que utilizan son el blanco, el rojo, el naranja, el amarillo, el verde y el azul, entre otros. Los colores utilizados por el grupo Wushe y el grupo Wanda en sus tejidos incluyen el blanco, el rojo, el azul y otros. Aunque el número de especímenes recogidos para este estudio es limitado, es posible entender cuáles son las preferencias de color de las subtribus a través de sus esquemas de color. Los esquemas de color más predominantes implican colores similares, colores contrastados y colores complementarios.

Palabras clave: Pueblos indígenas, Atayal, tejidos, color.

\section{INTRODUCTION}

\subsection{RESEARCH MOTIVATION}

With respect to both fiber and color the clothing material of Taiwan's indigenous people came predominantly from nature. Natural pigment extract is used for dye, along with the textile materials, are put through a dying process before being made into cloth, and finally used to produce clothing which can be worn. In the process of weaving and dying, the coordination of fabric patterns and color has a particular symbolism of its own for each tribe. The clothing of various indigenous peoples varies to different extents from tribe to tribe, and the garments each tribe wears have their own cultural or symbolic meaning. The woven materials of the Atayal People are a very distinct example of this.

The Atayal are the second largest tribe of Taiwanese indigenous peoples and, from an anthropological perspective, the Atayal include two major linguistic dialects: the Tayal and the Sediq. Their distribution extends from Taiwan's north to its central and eastern regions. From the north the area they cover includes Taipei County's Wulai and extends to Hualien County's Hsiulin Township, Shohsi Township, Wanrong Township, and other regions. The Atayal can be divided into as many as 25 subtribes, and their traditional costumes are the most unique among those of Taiwan's indigenous peoples. In view of this, this research performs comparative analysis with respect to Atayal traditional apparel to interpret its expression in color and better understand Atayal material culture.

\subsection{RESEARCH PURPOSE}

Prior to the Japanese occupation period (1895-1945), most of the Taiwan indigenous peoples participated in cloth weaving activities to some extent. In particular, women regularly carried out this task. Mori Ushinosuke (1917), Sato Bunichi (1942), and other Japanese scholars indicate the Atayal were excellent at weaving cloth, and excelled at creating both textiles and rattan-woven vessels. What is more, various sub-tribes of the Atayal exhibited different transformations in how they utilized color as a result 
of living in different environments. This also led to the gradual formation of different styles within each sub-tribe. The goals of this research are:

1. Understand what the colors in Atayal fabrics are intended to express, as well as their symbolic meaning.

2. Perform contrast analysis on Tayal and Sediq fabric colors to determine their similarities and differences.

\section{LITERATURE REVIEW}

In order to understand Atayal material culture, this research examines documentation on the Atayal people's clothing culture, the materials the Atayals use for making clothes, and Atayal traditional garb, as well as other aspects of Atayal clothing, and other documentation, in order to understand the symbolic meaning of Atayal fabrics and the techniques used to create them.

\subsection{THE CULTURE OF ATAYAL DRESS}

In discussing Atayal's Gaga (the core of Atayal culture), Tien Tze-I (2001, 233) asserts that Utux (the dead and their spirits) fear the color red. For this reason, this tribe wears clothing dyed dark red to frighten away these spirits. In addition, the rhombus pattern woven on the front of these garments represents the eye of the forefathers and is worn for protection. The design on the back of garments uses complicated woven patterns in order to ward off the Utux. From this we can understand the meaning of Atayal clothing culture is derived from the spiritual beliefs of its people and uses imagination, color, and patterns to construct shapes that do not represent any particular object from striped patterns. These abstract patterns can be attributed to tribal consciousness and represent a desire for the tribe's blessings and protection.

\subsection{ATAYAL WEAVING MATERIALS}

The Atayal and other indigenous people of Taiwan all use ramie as the primary material in creating fiber for weaving. During the Japanese occupation, in terms of color used for woven materials the Atayal jialadai group, Shejialu Group, the Wenshui Group, the Ma'aw Group, the Mstranan Group, and the Qinaer Group used black, white, red, yellow, blue, green, and purple (Taiwan Governor-General Office , 2010, p.150). The Wushe Group, the Taotuo Group, Zhuoluo Group, mostly used the colors purple, black, blue, yellow, white, red, and green. The Inside Taroko Group, External Taroko Group, Taosai Group, Mizhuolan Group, and Mugua Group predominantly used red, black, white, blue, yellow, pink, and purple (Taiwan Governor-General Office Temporary Taiwan Old Manners and Customs Survey Society, 2011, p.94, p.92). The primitive materials used in the past included the juice of plant roots which 
was extracted and used to boil the threads used to make clothing. For example, the sap coming from Dioscorea matsudae could be used to dye threads the brownish color of black tea. For black, threads were placed in lye, mud or smashed Lagerstroemia subcostata. By contrast, for ochre color, threads were placed in lye or a compound made with the pounded corm of cassava which was mixed with water.

\subsection{ATAYAL TRADITIONAL CLOTHING}

Traditional Atayal clothing integrates sewn and draped styles in its apparel. In general, the composition of traditional clothing can be divided into daily, work and ceremonial costumes. According to Tadasu (1999, p.79), Atayal clothing can roughly be divided into 7 categories. These include wide sleeved garments, vests, square robes, chest coverings, leggings, waste coats, capes (Figure 1), and other items. There are differences in the ornamentation men and women wear. For example, men wear hats, while women wear bandanas (Figure 2). Men's hats are woven from rattan, and some have a visor in the front, or a bear skin covering (with the neck covered with a half-moon shaped piece of fur). Ceramic buttons can also be used as decoration.

Figure 1 Both men and women of the Atayal wear capes

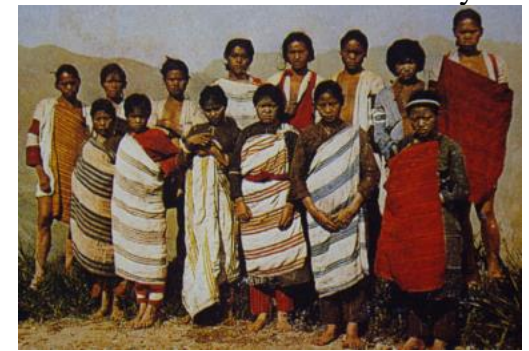

Source: The Beauty of Taiwan's Indigenous Peoples, p.28

Figure 2 Dress style of the Atayal nanshi group

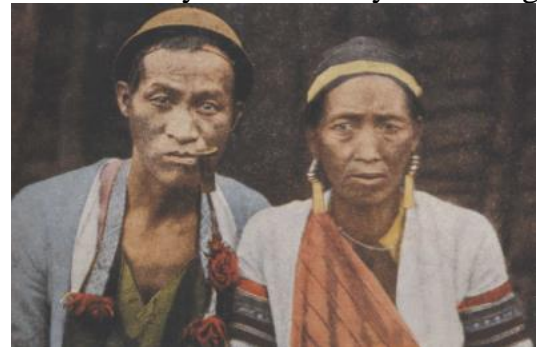

Source: The Exquisite Heritage-Culture and Art of Taiwan Aborigines, p.61

\section{RESEARCH SCOPE AND METHODOLOGY}

\subsection{RESEARCH SAMPLES}

Atayal costumes from earlier periods have now, for the most part, become part of museum or private collections, and at present it is difficult to find these in Atayal villages. From 1990, the Taichung Cultural Center was able to collect a large number of Atayal textile samples because of their location. At 
present, this Center is one of the larger collections of Atayal artifacts Taiwan in Taiwan. Therefore, this research takes museum collections as the object of its research. In organizing its research, this study takes 23 Atayal fabrics as its research sample, and takes these as the basis for understanding Atayal clothing (Figure 3).

Figure 3 Taichung Cultural Center Atayal fabrics Collection

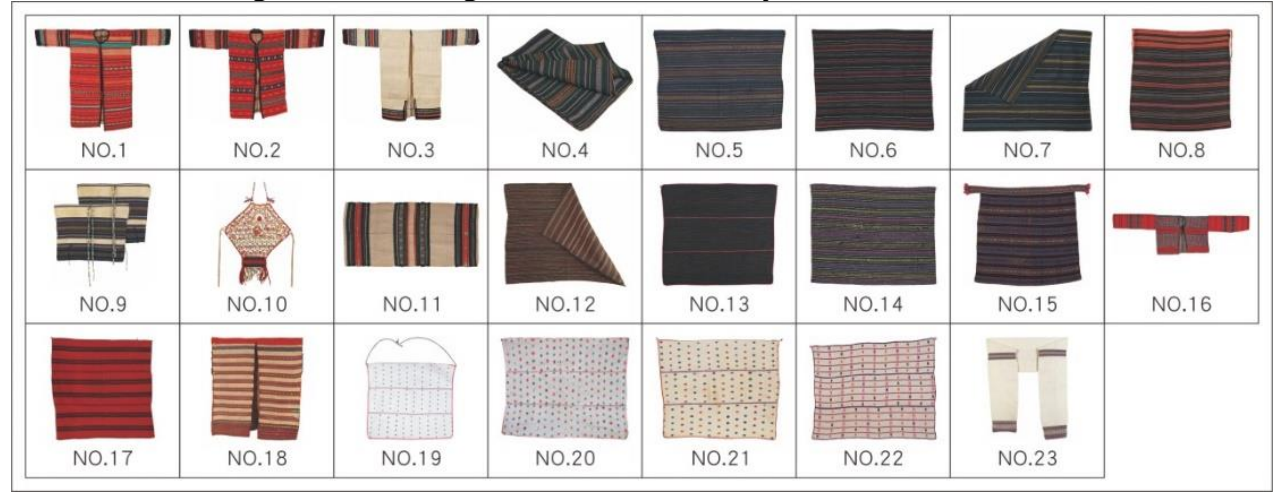

Source: Taichung Cultural Center

\subsection{COLOR COMPARISON}

In implementing this research, in addition to the question of commonality of use concerning colors in textile manufacturing, we also are concerned about the reflective nature in conditions concerning color. The standards put forward by PANTONE Company are accepted globally for color systems and researching color. Ultimately, this study chooses FASHION + HOME cotton planner's fabric color comparison system. In addition, for fabrics color cope description, we use the Live Scheme color wheel function from Color Schemer Studio (color analysis software) and input the color samples derived from fabric comparison one by one to understand Atayal fabric color schemes.

\section{ATAYAL FABRIC COLOR ANALYSIS}

The sample of this research is the 23 items of the Atayal fabrics from the Taichung Cultural Center: Beishi group (Miaoli County Taian Township, Taichung County Heping Township) 1; Malikoan group (Nantou County Ren-ai Township and Sinzu County Jianshih Township)1; Quchi Group and Dakekan Group (Taipei County Wulai Township and Taoyuan County Fuxing Township) 1; Nanao Group (Yilan County Nanao Township and Datong Township) 2. The Sediq's samples are as follows: Wushe and Wanda Groups (Nantou County Renai Township) 2; Taroko group (Nantou County Renai Townshipand Hualien County Hsiulin Township, Wanrong Township, Chohsi Township, Jianshih Township, and other areas of Hualien) 6. In the section below this research analyzes research specimen color. 


\subsection{TAYAL: BEISHI GROUP}

NO.1, NO.2 women's long sleeved bridal dresses; NO.3 male garment with jacquard; NO.4 women's wrap skirt, NO.5, NO.6, NO.7, NO.8 male and female shawls; NO.9 women's foot cloth; NO.10 men's chest covering; NO.11 piece of fabric. The color coordinating techniques of Beishi group clothing involve putting together similar colors, contrasting colors, and complimentary colors. The swath of black fabric on garment cuffs is one of the unique characteristics of Beishi group garments. In particular, the sleeves of garments have varied and bountiful coloration in its stripes. In addition, black, red and white being the main colors coordinated together for the clothing's rhombus pattern in order to make the fabric pattern stand out. The color composition of the Beishi group's wrap skirts, shawls, and foot cloth utilize black or dark blue as their base color, and their stripes and composite stripes are composed of various colors. Composite stripes are organized from two to four different colors, and striped garments usually include one color stripe with one other color lined up with them. The coordination of one dark color and one light color makes the different layers of color visible. The color arrangement of NO.10, the men's chest covering, and the NO.11 cloth piece, are representative of the Beishi group clothing style. This is also the case for the color coordination of the clothing items in NO.1, NO.2, and NO.3 (Figure 4). While we have no way of absolutely determining the origin of NO.10's fabrics, we can infer that it belongs to this sub-tribe from its colors.

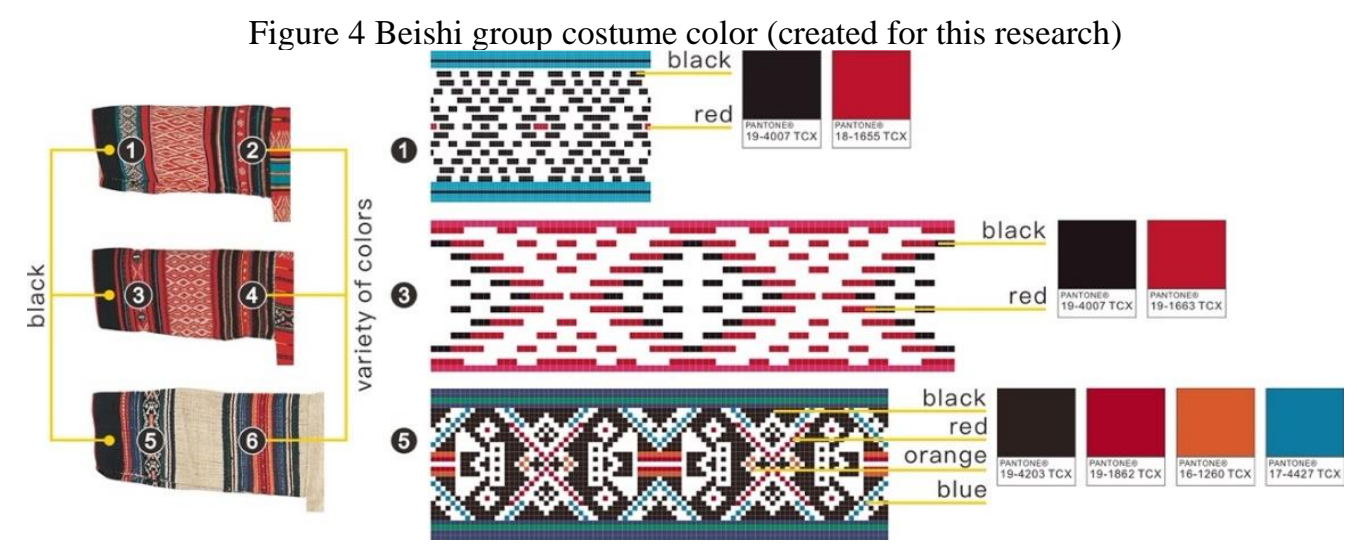

\subsection{TAYAL: LIKOAN GROUP, QUCHI GROUP AND DAKEKAN GROUP}

The fabric of sample NO.12, a men's shawl, lacks the richness and abundance of Beishi Group fabric colors. Its main color is black (PANTONE 19-4007 TCX) coordinated with white (PANTONE 110601 TCX), orangish yellow (PANTONE 16-1142 TCX). The color composition of the composite stripes includes black, orangish yellow and white (Figure 5), and the color composition of the stripes includes black, orangish yellow, and white. The fabric composition of the NO.13 women's wrap skirt is very succinct with a black foundation (PANTONE 19-4007 TCX) coordinated with white (PANTONE 11- 
0601 TCX), and pink (PANTONE 19-1955 TCX). The color composition of the composite stripes includes black and white (Figure 6). The fabrics of the Malikoan group, Quchi Group and Dakekan Group use fairly simple color compositions. However, as there is only one specimen for these groups at present, it is impossible to make any definitive conclusions.

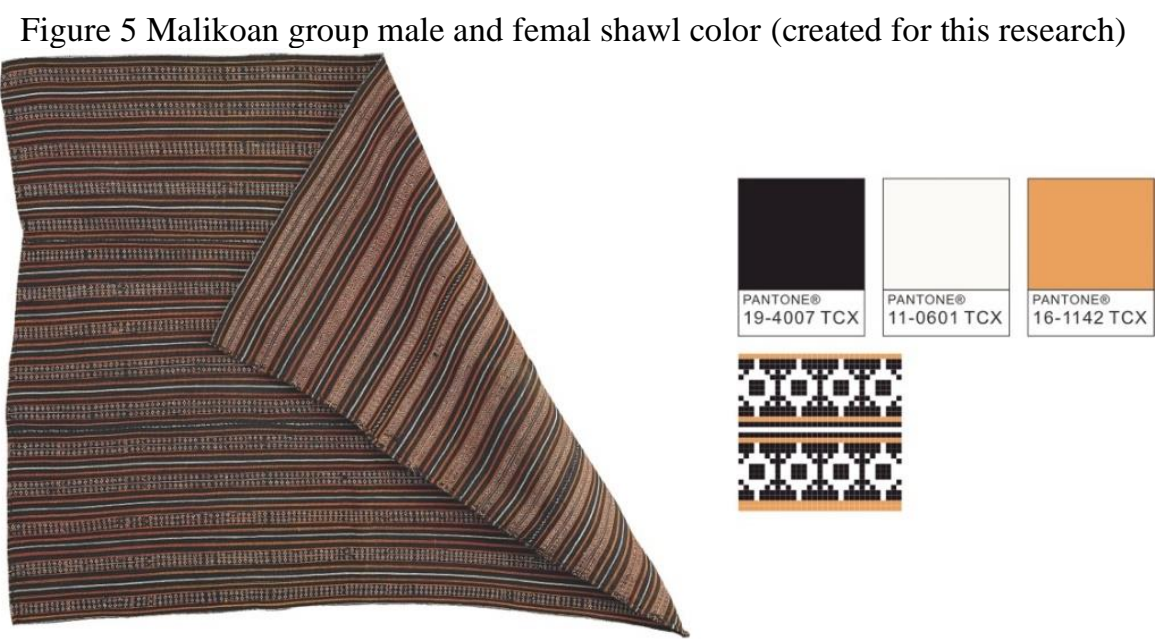

Figure 6 Quchi group and Dakekan group women's wrap skirt color (created for this research)
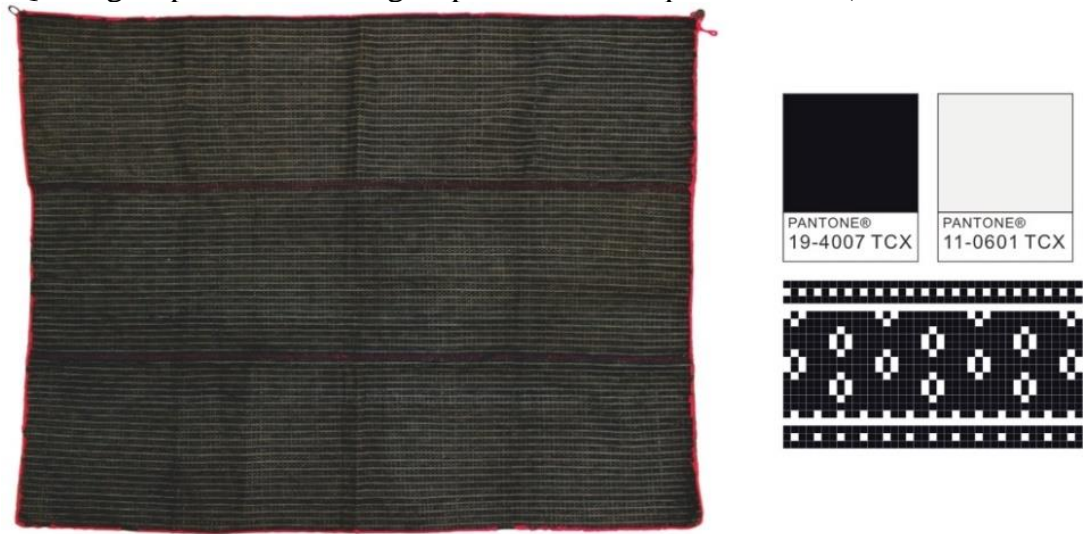

\subsection{TAYAL: NANAO GROUP}

The fabrics for NO.14 and NO.15 similarly both have surfaces filled with composite stripes and stripes, and have a fabric pattern with the stripes intertwined with one another. The color coordinating techniques of the Nanao Group include matching similar colors, contrasting colors, and complimentary colors. While NO.14 (Figure 7) and NO.15 (Figure 8) have different fabric patterns, their color compositions are identical. The color of the stripes is more striking than those of the Beishi group. 
Figure 7 Nanao group men's shawl color (created for this research)
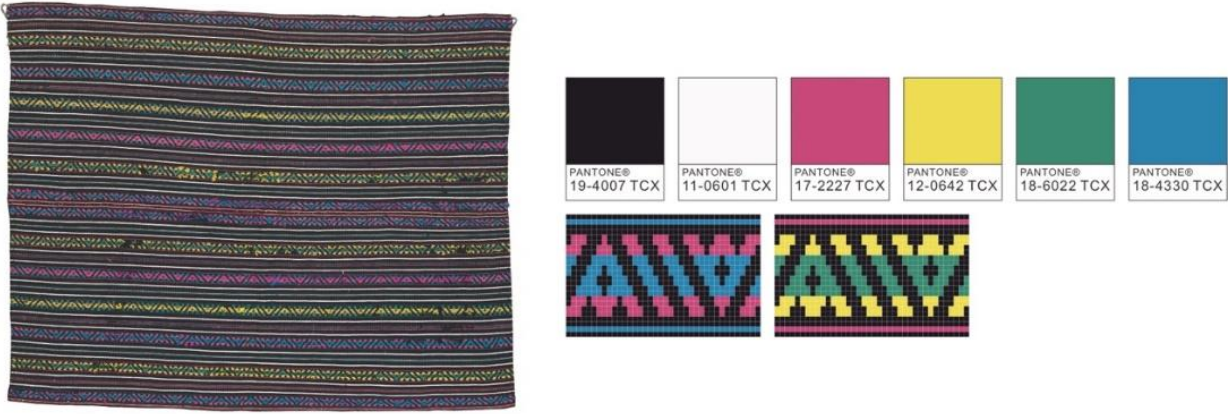

Figure 8 Nanao group men's shawl color (created for this research)
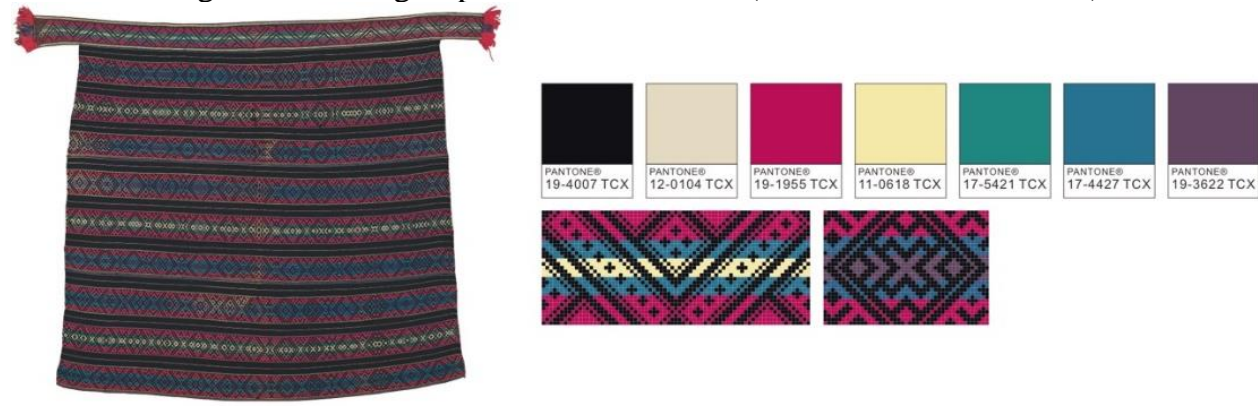

\subsection{SEDIQ: WUSHE GROUP AND WANDA GROUP}

The fabric color composition of NO.16, the women's long sleeve shirt and NO.17, the men's shawl, are similar in that they both use black and red primarily with black colored stripes. NO.16 has a red base (PANTONE 19-1663 TCX) coordinated with black (PANTONE 19-4007 TCX), dark blue (PANTONE 19-4110 TCX), and white (PANTONE 11-0601 TCX). The composite stripes color composition includes: red, black, dark blue, and white (Figure 9); and red, black, and white. NO.17 has red as its base color (PANTONE 19-1664 TCX) coordinated with black (PANTONE 19-4007 TCX), deep yellow (PANTONE 14-0941 TCX), and green (PANTONE 16-6138 TCX). The rhombus pattern color composition includes red and dark yellow. The stripe color composition includes: red, black, and green.

Figure 9 Wushe group, Wanda group long sleeve shirt color (created for this research)
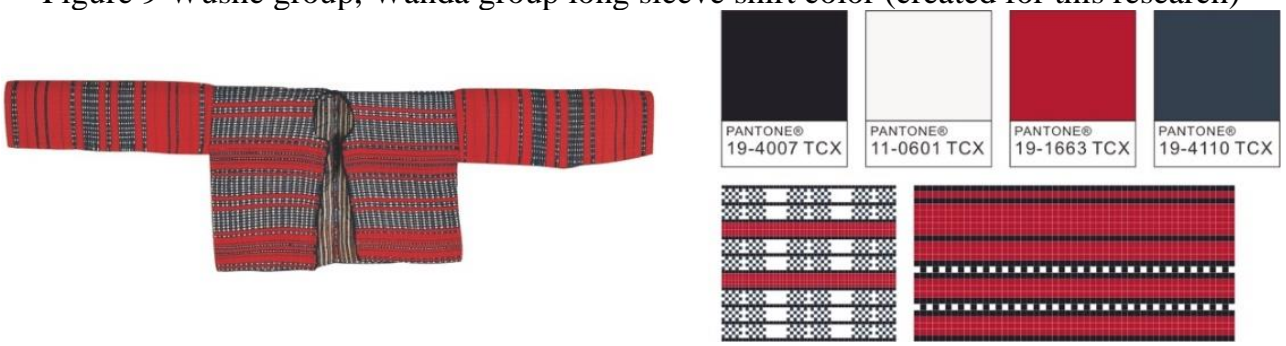

\subsection{SEDIQ: TAROKO GROUP}

NO.18 men's sleeveless upper body garment; NO.19 women's wrap skirt; NO.20, NO.21, and NO.22 male and female shawl; NO.23 women's sleeve cover. The colors used most often in Taroko group 
garments include white or grey. Stripes of various color overlap in their fabric patterns. NO.18, a men's sleeveless upper body garment, has red as its main colors and is covered in jacquard weaves on both front and back. We can assume this item is only worn on special occasions, such as the ceremonies or rituals. It is most likely a ceremonial garb worn for religious festivals (Figure 10). NO.19, a women's wrap skirt, and NO.20 (Figure 11), NO.21, NO.22, a male and female shawls, as well as NO.23, a women's sleeve cover, all have similar fabric compositions. They all have a white or grey base decorated with rhombus patterns and a composition of different colors intertwining in their striped pattern. NO.23, a women's sleeve cover, has a similar style of adornment with on cuffs with NO.1, NO.2 and NO.3.

Figure 10 Taroko group men's sleeveless upper body garment color (created for this study)
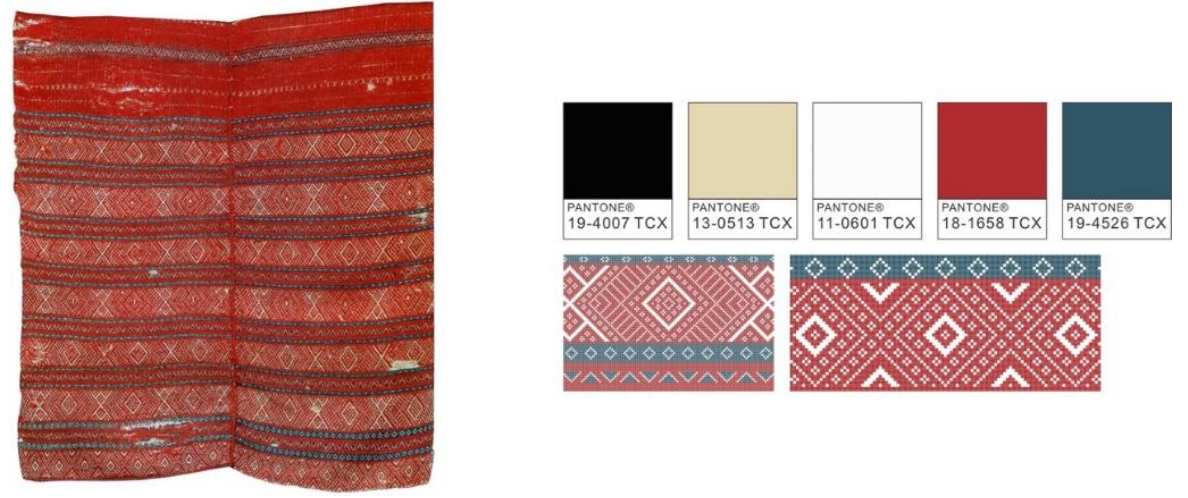

Figure 11 Taroko group male and female shawl color (created for this study)
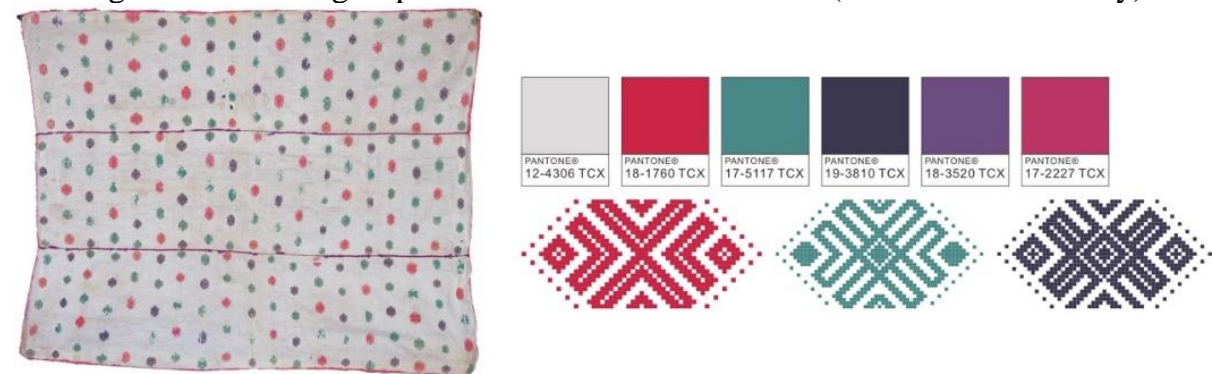

\section{CONCLUSION}

This sections sums up the above analysis of Atayal fabric color, for which, at present, there are a relatively large number of research specimens for sub-tribes such as the Tayal, which include the Beishi group and the Nanao Group, and the Sediq, which includes the Wushe Group, the Wanda Group, and the Taroko group. Our research takes these research samples and inputs them one at a time into ColorSchemer Studio's color software and performs colorscope analysis. The beshi Groups color use for fabrics is comparatively wide ranging and they use a diverse number of color combinations which mainly include black, white, red, orange, yellow, green, blue, and others (Figure 12). The colors used by the Nanao Group include black, red, yellow, blue, and others (Figure 13). The Wushe Group and Wanda Group fabrics utilize the colors black, white, red, blue, and others (Figure 14). Taroko group fabrics are white, red, green, 
blue, and others (Figure 15). While this research presents a limited number of samples for research, through color an examination of color distribution, we can understand preferences in sub-tribe specimens tend to express themselves with similar colors, contrasting colors, and complimentary colors.

Figure 12 Beishi group fabric color distribution (created for this study)

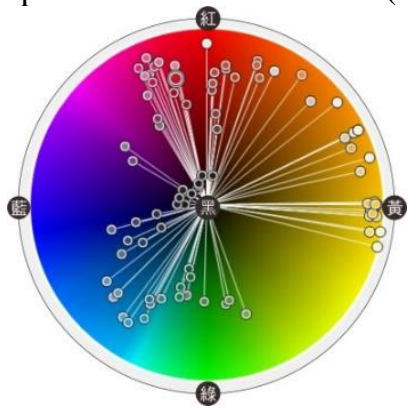

Figure 13 Nanao group fabrics color distribution (created for this study)

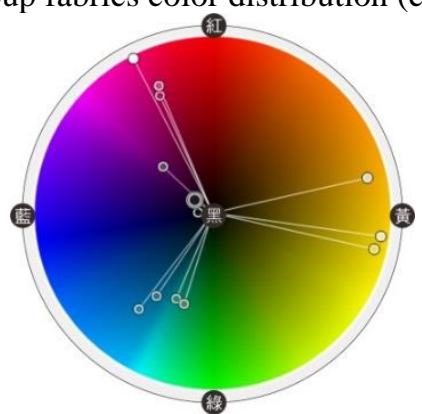

Figure 14 Wushe group, Wanda group fabric color distribution (created for this study)

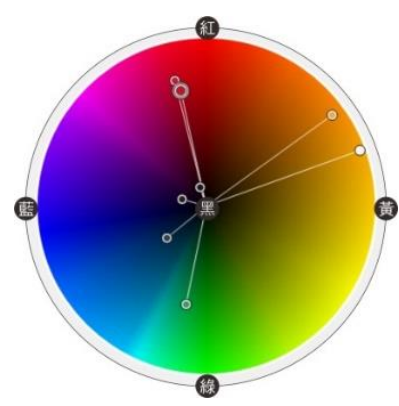

Figure 15 Taroko group fabric color distribution (created for this study)

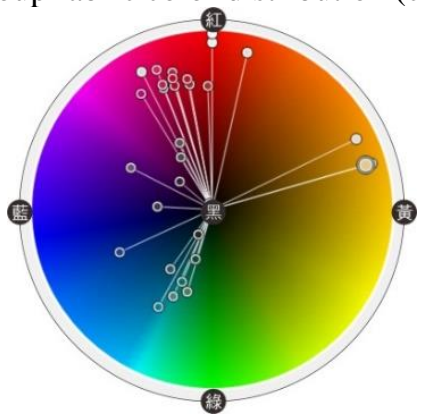




\section{REFERENCES}

Wang Wei-chang, 2002, The Beauty of Taiwan's Indigenous Peoples, Taipei: Yuanliu.

Taiwan Governor-General Office Temporary Taiwan Old Manners and Customs Survey Society, Trans. Academia Sinica Institute of Ethnology, 2010, Investigations into the Customs of Aboriginal Peoples Volume 7, Atayal, Part 2. Taipei: Academia Sinica Institute of Ethnology.

Taiwan Governor-General Office Temporary Taiwan Old Manners and Customs Survey Society, Translated by Academia Sinica Institute of Ethnology, 2011, Investigations into the Customs of Aboriginal Peoples -Volume 4, Sediq and Taroko Peoples, Taipei: Academia Sinica Institute of Ethnology.

Tung Chun-fa, 1996, The Exquisite Heritage-Culture and Art of Taiwan Aborigines, Taipei: Lihong.

Tien Tze-i, 2001, Taiwan's Indigenous peoples-Atayal, Taipei: Taiyuan.

Suzuki Tadasu, Trans. Wang Mei-jing, 1999, Customs of Taiwan's Indigenous Peoples, Taipei: Yuanminwenhua.

Mori Ushinosuke, 1917, Record of Taiwanese Aboriginals (Vol. 1), Taipei: Nantian.

Sato Bunichi, 1942, Research on the Primitive Art of Taiwan's Indigenous Races, Taipei: Nantian. 